\title{
Effective Organizational Communication using Metaphor: Homeplus Case
}

\section{Jinwook Kim, Insook Kim}

\author{
Kyunghee University, Seoul, Korea
}

Objectives: This article presents a case-based study on how CEOs can communicate effectively with members of their organization. Many CEOs deliver messages to employees to implement their management philosophy and encourage successful management performance. This study explored how these messages can be effectively disseminated to and internalized by employees throughout an organization.

Methods: This study investigated communication using metaphors carried out by the CEO of Homeplus, a representative retail company in Korea, from the time of its founding. These metaphors played an important role in achieving high management performance compared to competitors by promoting effective understanding and application of management principles to business.

Results: Management by metaphor (MBM) was defined as "using metaphor as a means of management." In this management method, the CEO utilizes metaphors in communication with stakeholders, including members of the organization, customers, and shareholders. Concepts such as corporate vision, management ideology, shared values, business concepts, leadership, talent, and basic principles are incorporated into metaphors and shared internally and externally.

Conclusions: Metaphors are very effective for clearly sharing management concepts within an organization. MBM can be widely used in negotiations, persuasion, contracts, and human networks in business relationships, including activities outside the company. Communication within organizations has always been difficult and a source of problems. However, in a business environment, metaphors act as a catalyst to facilitate effective communication.

Key Words: Metaphor, Communication, Management, Homeplus, Vision House

\section{Introduction}

Not all the phrases that people say will be memorable. The former CEO Seung-Han Lee (hereafter referred to as "SH Lee") of

Received: Sep 13, 2020 Revised: Oct 27, 2020 Accepted: Dec 18, 2020 Corresponding author: Jinwook Kim

24 , Kyungheedae -ro , Dongdaemun -gu , Seoul 02453, Korea

Tel: +82-31-811-7038, E-mail: trustjin@khu.ac.kr

This is an Open Access article distributed under the terms of the Creative Commons Attribution Non-Commercial License (http://creativecommons.org/licenses/ by-nc/4.0/) which permits unrestricted non-commercial use, distribution, and reproduction in any medium, provided the original work is properly cited.

Copyright $\odot 2021$ Korean Association for Business Communication.
Homeplus, a representative retail company in Korea, recognized the importance of using metaphors and actively used various metaphors in the business field to convey his management philosophy and message. SH Lee emphasized that metaphor is the most efficient means of keeping listeners engaged, invested, and motivated for a long time, especially as a corporate manager, arguing that metaphors will have a significant impact on management. Thus, SH Lee was convinced that management by metaphor (MBM) is an effective way to share managerial thoughts within an organization, encourage members to act, and improve corporate performance.

$\mathrm{SH}$ Lee expressed what he considered to be the most important management concepts, including the Homeplus man- 
agement philosophy and corporate culture, as metaphors. His metaphors were based on shared values and the organizational culture among its members, and he believed that the stronger the organizational culture, the more effective MBM as a management technique would be. Strong companies have their own language, habits, and unique organizational cultures. In particular, companies are characterized by their global scope covering many diverse cultures. MBM can be used as an important means for building a strong corporate culture within outstanding companies.

\section{Origin of Metaphor}

Metaphors are commonly used for communication. That is, we use metaphors to express the same meaning regardless of who the listener is. In the word "communication," "com" means "together," and "muni" means "mutual." As such, metaphor is a method of communication and a means of connecting with each other through language and gestures (Keysar \& Glucksberg, 1992). Metaphors enable communication at a higher level. The ultimate purpose of communication is to understand the nature of the message being conveyed to the listener, and as a result, the speaker achieves the intended effect. To convey, accept, and understand the essence of a message, there must be shared values between the speaker and the listener. When these shared values establish a mutual premise between speaker and listener, it is possible to convey meaning close to the essence of a message. Hawkes (1972) argued that metaphors express a more accurate meaning by using figurative meaning to transfer a message, which leaves its own separate impression and makes the message seem new, larger in scope, or more specialized. The purpose of metaphors lies in a sense of inadequacy based on a new level of perception, referred to as "deviant predication" (Smith, 2013).

In addition, Ullman (1957) argued that the distance between an original idea and an auxiliary idea is an important feature of metaphors. This means that the similarity between the original idea and the auxiliary idea must be accompanied by a sense of discrepancy. When given a new metaphor, humans apply their hermeneutic instinct; since a metaphor is a device to understand one thing through another, choosing to use a metaphor is a hermeneutic act (Burke, 1969). The use of metaphors enables efficient communication. Instead of a long description, it is possible to convey content concisely through other objects or ideas with similar characteristics. Metaphors are also advantageous for effective communication. If a message is abstract, explaining it in relation to specific objects through a metaphor increases the possibility that the audience will accurately understand it.

Therefore, it can be said that SH Lee's MBM was not entirely new, but instead reflects an attempt to systematize and synthesize existing metaphors in business administration research, the management field, and communication methods of leaders.

\section{Why Management by Metaphor?}

Digital technology is a new trend that has had a wide-ranging impact on the economy, society, and culture, and especially on corporate management. The reason for the transformations induced by digital technology is that in a business environment dominated by the internet, computers, and information technology, flexibility based on the creativity of the members of the organization, as opposed to the strength of a united organization like in the past, determines a company's competitiveness. Organizational structures are also changing to become more horizontal to respond to rapid changes. A horizontal organizational structure of a company is based on agility and creativity, and in addition to improving coping ability, it also broadens the view of business and competition (Appelbaum, Calla, Desautels, \& Hasan, 2017).

Leadership plays an increasingly important role in companies with an emphasis on individual autonomy as a way to move employees in a single direction (Slemp, Kern, \& Patrick, 2018). To show outstanding leadership in the future, it is necessary to present a clear vision and shared values through prompt and effective communication. Regarding the concept of positive leadership, which has recently attracted attention, positive communication within the organization, a positive atmosphere, and positive relationships are presented as the most important strategies. In shared leadership, success depends on the collective behavior or shared culture of many team members beyond specific individuals. Both types of leadership can be implemented successfully based on good communication within the organization.

SH Lee defined metaphors as "means that effectively and efficiently convey meaning through metaphors" and a "communication hoisting method." MBM was defined as "using the metaphor as a means of management" (Kim \& Chang, 2018). In other words, MBM is a management method that utilizes metaphors for communication with stakeholders, including members of the organization, customers, and shareholders, from the perspective of the CEO. All concepts such as corporate vision, management ideology, shared values, business concepts, leadership, talent, and basic principles are incorporated into metaphors and shared internally and externally.

The use of metaphors is very effective in clearly sharing important management concepts within an organization and forming consensus among members in the shortest possible time. MBM can also be widely used in negotiations, persuasion, contracts, and 
human networks in business relationships outside the company. Communication within organizations has always been difficult and a source of problems. However, in a business environment, metaphors act as a catalyst to facilitate effective communication.

\section{Case Description}

\section{Birth of Homeplus and Metaphor}

SH Lee's "metaphors" began when the company's brand was created. In 1996, when Homeplus was preparing to start a business, most discount stores in South Korea had names ending in "mart." In this flood of "marts," SH Lee was looking for a familiar brand name that would be easy to pronounce and could be remembered immediately, while retaining the perception of discount stores where good products can be bought at low prices. He created a brand called "Homeplus," linking "Home" and "Plus," the motto of which ("let's be helpful to the family, let's be helpful to life, and be a plus to family life") was created in 1997 after numerous evaluation processes.

\section{Effectiveness of Metaphor-Based Communication}

SH Lee explained the effectiveness and application of metaphor-based communication with the following four requirements. The first is ease of understanding. Metaphors are simple and concrete expressions that are easy to convey and understand. The second is stimulation and impressiveness. A metaphor gives the audience a strong stimulus and excitement that cannot be given by a general description. The third is the effect of memorization and embedding. Strong stimuli, emotions, and stories contained in metaphors can remain in a listener's memory for a long time. The fourth is execution following a communication. Through these steps, a metaphor influences the listener to act effectively and efficiently.

Metaphors are attractive in management since they encourage implementation among members of an organization. In addition, the use of metaphors in this process has the advantage of stimulating creative thinking since metaphors deliver messages indirectly, rather than through direct instruction. Metaphors inspire members to act on their own since they support active and autonomous behavior rather than passive attitudes. Metaphors are also fast-spreading, have a wide reach, and encourage an easygoing atmosphere in the organization due to their humorous and fun nature. Because of these advantages, SH Lee has widely implemented MBM. Metaphor is a very effective means for leaders to guide various people in the organization in a cohesive direction. Thus, SH Lee believed that the use of metaphors had an overall impact on corporate management.

\section{Examples of Metaphor-Based Communications}

\section{Store Manager's Shoes and Chairs}

The impressions left by messages that leaders deliver through metaphors have the power to raise the work by members of an organization to the highest level. Knowing the merits of using metaphors, SH Lee presented a new store manager with a chair with the manager's name on it and new shoes. "Our managers are at the level of cabinet members in the US. In our roles at Homeplus, we meet local residents and contribute to local development. These two gifts symbolize that you will not lose your dignity as a manager when you sit in a chair and work hard for customers, or when you go to the store and work hard enough to wear out the heels of your shoes."

The chair with the manager's name on it was inspired by the chairs of U.S. cabinet members that SH Lee saw in a conference room while visiting the White House. The principle of this gift was that if someone works in a chair with his or her name engraved on it, he or she will have no choice but to feel a sense of responsibility and mission. Shoes represented SH Lee's idea that, in the distribution industry, on-site management is important for checking and overseeing work. The new branch managers who received such gifts from the CEO would feel the need to be prepared for such work.

\section{Homeplus as the "Customer Council"}

Just as brands have a BI (Brand Identity), companies have a CI (Corporate Identity), and people have a PI (Personal Identity), Homeplus was the first brand in the retail industry to account for the identities of individual stores. SH Lee first introduced the concept of the SI (Store Identity) in Ansan, having judged that the value of a store would be even higher if it was possible to give an identity to the place where the customer and product meet. When talking about Homeplus' SI, he often referred to Homeplus as a clock tower that can be recognized at a glance, which contains a much deeper meaning. The unique, clocktower-shaped exterior is a reference to British Parliament's Big Ben, which is located in a historic area on the banks of the Thames River. If a National Assembly Hall represents the opinions of the people in each country, then a discount store that collects customers' opinions can be thought of as the Customer Hall. In other words, Homeplus' "customer council" spirit, which reflected the goal of satisfying customers' needs in a comprehensive manner, was expressed in the design of the store.

Homeplus' SI has created a unified brand image of "plusto-life," starting with the symbolic weight of the clock tower, followed by a moving walkway, front window design, entrance design, the exterior wall design of the parking lots, and vehicle entrance design. This design reflects not only an impressive 
appearance, but also the heart of the company, which places customers first.

\section{"Vision House" as a Management Frame}

Another notable point in SH Lee's MBM is the introduction of geometric elements to the metaphor. This practice entails compressing and visualizing linguistic metaphors represented by words, sentences, and stories into geometric representations containing schematics, pictures, and symbols. This method was developed after many years of thought in order to enable the sharing of metaphors containing one's philosophy within an organization more quickly, easily, and interestingly. Therefore, geometric elements were included in the message and training programs that SH Lee developed for his employees in the field. The definition of management is generally described as a form or process (Rue \& Byars 2000) that directs people to achieve an organization's purpose or goal. The principle of success is to strictly define each concept one-by-one and share it with all members of the organization (Milton, 1982). As a representative example, each symbol describing a component of the "Vision House" is a concise and easy-to-remember symbol that organically shows its relationship to the relevant elements of management (Figure 1).

\section{Future Management with Metaphors}

In his 44 years of work experience, SH Lee encountered many cases where small business managers lacked knowledge and theory about management. He also shared the difficulties that managers face in the process of sharing, spreading, and implementing new strategies and visions on behalf of the company. Since SH Lee also faced these same difficulties before becoming $\mathrm{CEO}$, he created the foundation of $\mathrm{MBM}$ to improve commu-

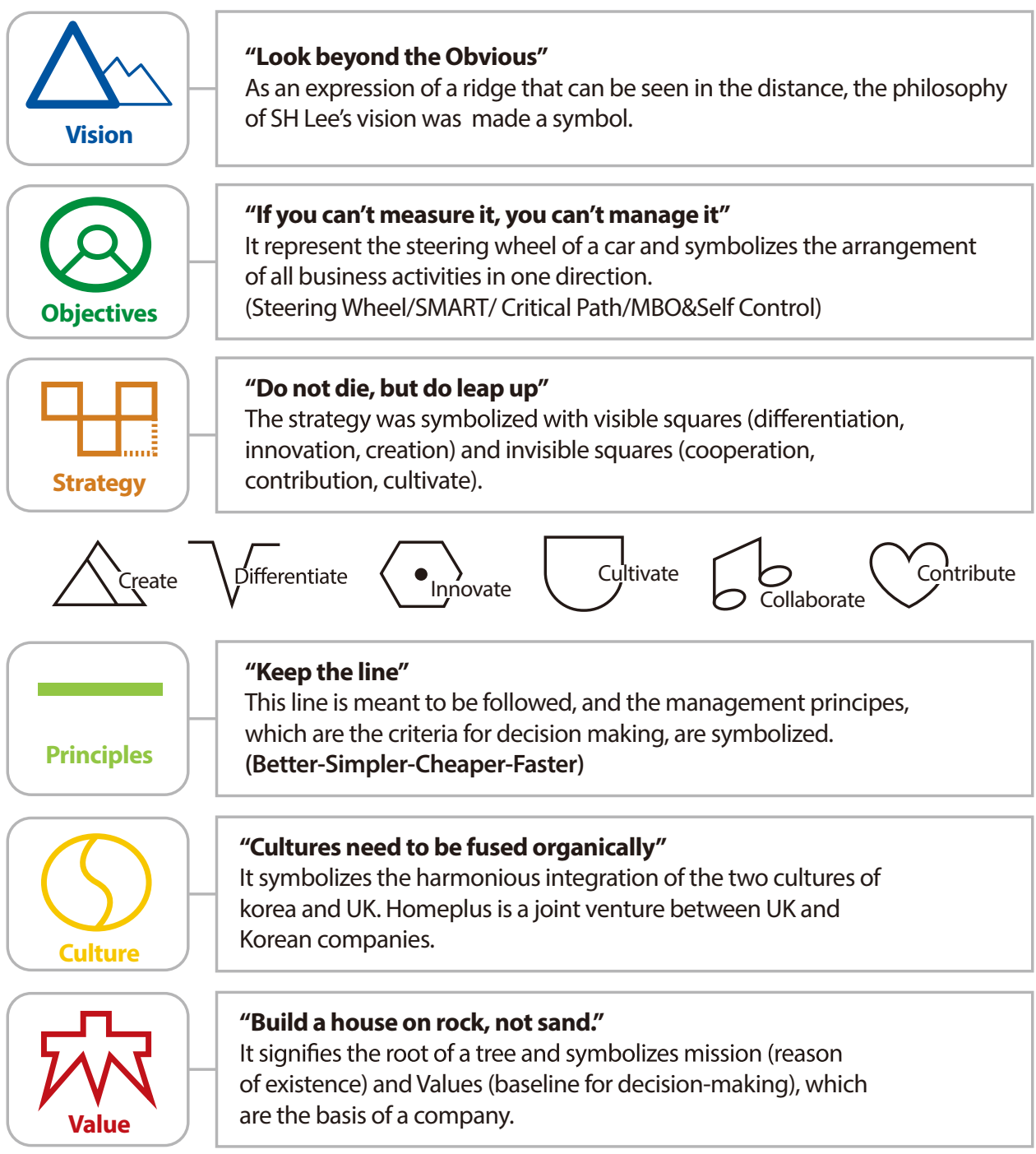

Figure 1. Elements of the "Vision House." 
nication with managers, and he refined and developed MBM while applying it to the management field for a long time. $\mathrm{SH}$ Lee believes that future management reflects the concepts of "other-connectedness," "helpfulness," and "open collaboration" beyond the dimension of self.

Beyond the self, the ability to actively discover, utilize, and collaborate with others is required to act within and outside an organization. SH Lee believed that if the sharing of goals and directions within an organization become active through MBM, collaboration would be smooth and strengthen corporate competitiveness. He also expected that companies would take the lead in contributing to community development based on the value of connecting others. As such, SH Lee believed that MBM could contribute to a better tomorrow based on support for small and medium-sized enterprises and promoting the social contributions of companies.

\section{Discussion}

\section{Making the Organization More Active through Metaphors}

To understand and manage an organization effectively, one must have the ability to manage the organization according to various perspectives and sophisticated analytical frameworks. The foundation of organizational research is built by analyzing unique perspectives and methods that recognize a diversity of perspectives in organizations. Organizational metaphor analysis is one of these methods and can be used as a tool to analyze organizations. Morgan (2006) presented eight metaphors as ways of looking at organizations, including machinery, organisms, brains, culture, political systems, psychological prisons, constant conversion processes, and governance tools. Morgan, in particular, used the example of Frederick the Great of Prussia, who turned his military into a mighty army based on inspiration from a moving toy soldier that wound and turned a spring leaf, providing an image of regularity that served as a basis for his organizational innovations (Morgan, 2006).

Palmer and Dunford (1996) pointed out that research using metaphors is actively conducted in organizational decision-making, leadership, organizational change, organizational development, policy, strategy, organizational culture, and organizational design, and emphasized the importance of metaphors in organizational research. French and Bell (1999) also argued that metaphors were very helpful for understanding organizational change, citing Lewin's three-step model of change (thawing $\rightarrow$ change $\rightarrow$ refreezing) for organizational development.

\section{How to Manage by Metaphor}

SH Lee emphasized that the core of metaphor communication is an art. In particular, he said in an interview with Forbes Korea that he is inspired by modern art, saying "Contemporary art is to make 'something not special' into 'something special." He believed that art is what makes ordinary things extraordinary, as seen in Andy Warhol's (1928-1987) works incorporating images of boxes and toilet bowls. SH Lee insisted that the power of art comes from making general things special from the perspective of the artist, and that management should be recognized as art. SH Lee also received constant intellectual stimulation in his daily life through meetings with numerous people, forums, seminars, listening to and giving lectures, and mentoring based on extensive reading.

The driving force behind this search for knowledge is active curiosity. SH Lee is truly interested in a broad range of subjects, which he makes his own. He also uses his imagination to connect completely different concepts. Art, curiosity, and imagination are the basis for improving creativity, which can be used to create excellent and effective metaphors. In that spirit, SH Lee tried to express metaphors without restrictions in paintings, symbols, and buildings by using visual and geometric elements. Metaphors that use geometry and symbols are an important feature of SH Lee's MBM.

\section{Conclusion}

To successfully use metaphors to communicate, it is first necessary to clarify the goal of what one wishes to express. When selecting the source domain, the audience's knowledge level, attitudes, and cultural backgrounds must be considered. In other words, one must think carefully to find a metaphor that listeners can understand easily. One should then design the most compact and simple sentence, word, or picture to communicate the metaphor. Metaphors also encourage the audience to see or hear and act. If one repeats certain processes one after another, a metaphor comes to mind (Spark of Genius), but it can also be said that a metaphor is revealed at the moment when it is needed, through the fusion of SH Lee's 44 years of experience in management and life, vast curiosity, and artistic sensibility. On this basis, SH Lee's expressions satisfy the conditions of an excellent metaphor. In other words, his metaphor had a prompt impact, so that members of the organization could grasp his thoughts and intentions and act accordingly.

\section{References}

Appelbaum, S. H., Calla, R., Desautels, D., \& Hasan, L. N. (2017). The challenges of organizational agility: Part 2. Industrial and Commercial Training, 49(2), 69-74. 
Burke, K. (1969). A grammar of motives. Berkeley, CA: University of California Press.

French, W. L., \& Bell, C. H. (1999). Organization development: Behavioral science interventions for organization improvement. Upper Saddle River, NJ: Prentice-Hall.

Hawkes, T. (1972). Metaphor. London, UK: Methuen.

Keysar, B., \& Glucksberg, S. (1992). Metaphor and Communication. Poetics Today, 13(4), 633-658.

Kim, I. S., \& Chang, Y. C. (2018). The case study of metaphorical approach of management. The Review of Business History, 85, $1-22$.

Milton, L. (1982). Choosing the right manager to fit the strategy. Journal of Business Strategy, 3(2), 58-69.

Morgan, G. (2006). Images of organization. Thousand Oaks, CA:
Sage.

Palmer, I., \& Dunford, R. (1996). Reframing and organizational action: The unexplored link. Journal of Organizational Change Management, 9(6), 12-25.

Rue, L. W., \& Byars, L. L. (2000). Management: Skills and application. Boston, MA: McGraw-Hill Irwin.

Slemp, G. R., Kern, M. L., Patrick, K. J., \& Ryan, R. M. (2018). Leader autonomy support in the workplace: A meta-analytic review. Motivation and Emotion, 42(5), 706-724.

Smith, P. (2013). Lead with a story (Y. S. Kim, Trans.). Seoul, Korea: IGMbooks. (Original work published 1981).

Ullman, S. (1957). Style in the French novel. Cambridge, UK: Cambridge University Press. 